\title{
FILOSOFIA E CIÊNCIA EM NIETZSCHE ${ }^{1}$ [Philosophy and Science in Nietzsche]
}

\author{
Eder Corbanezi ${ }^{2}$
}

\begin{abstract}
Resumo: Pretendemos tratar de alguns aspectos da relação entre filosofia e pensamento científico em Nietzsche. De início, procuraremos indicar as diversas maneiras pelas quais a ciência se faz presente em sua trajetória, bem como algumas das motivações que o levaram a dialogar com o domínio científico. Em seguida, examinaremos a dimensão programática que tal diálogo assume no contexto da filosofia histórica nietzschiana, que não se deixa pensar separadamente da ciência, ou melhor, que só pode ser concebida em virtude do nível alcançado pelas ciências em sua época. No momento subsequente, analisaremos a face conflituosa da relação entre filosofia e ciência: ao se opor à pretensão de emancipação da ciência e ao preconizar o domínio da filosofia sobre a ciência, Nietzsche reserva uma tarefa própria à filosofia - resolver o problema dos valores - e com isso lhe garante uma posição hierarquicamente superior. Por fim, apresentaremos uma última dificuldade: embora a tarefa filosófica de resolver o problema dos valores tenha de se basear nas ciências, a própria ciência se encontra sob o jugo de certos valores predominantes à época de Nietzsche, mas criticáveis aos seus olhos.
\end{abstract}

Palavras-chave: Nietzsche; epistemologia; ciência; filosofia da ciência

\begin{abstract}
We intend to discuss some aspects of the relationship between philosophy and scientific thought in Nietzsche. At first, we will try to indicate the various ways in which science is present in his trajectory, as well as some of the motivations that led him to dialogue with the scientific domain. In the sequel we will examine the programmatic dimension that such a dialogue has in the context of Nietzsche's historical philosophy, which cannot be thought separately of science, we mean, which can only be conceived in the context of the level achieved in science in his day. Further, we will analyze the conflicting relationship between philosophy and science: opposing the emancipation claim of science and advocating the superiority of philosophy in relation to science, Nietzsche reserves a specific task to philosophy - to solve the problem of values - and thus guarantees its position of superiority. Finally, we will present a final issue: although the philosophical task of solving the problem of values has to be based on science, science itself is held captive of certain prevailing values at the time of Nietzsche that are indeed reprehensible to his eyes.
\end{abstract}

Keywords: Nietzsche; epistemology; science; philosophy of science

\footnotetext{
${ }^{1} \mathrm{O}$ texto aqui publicado foi apresentado em forma de comunicação durante o XXXVII Encontros Nietzsche: Nietzsche e o pensamento ocidental, realizado em 1 e 2 de outubro de 2015 na Universidade Católica de Pernambuco, no Recife. Citamos preferencialmente a obra de Nietzsche na tradução de Rubens Rodrigues Torres Filho (RRTF), em Friedrich Nietzsche: Obras incompletas. Nos demais casos, as traduções são de nossa responsabilidade, a partir da Kritische Studienausgabe (KSA) e da Kritische Gesamtausgabe (KGW). Às siglas em alemão, convencionadas em KSA 14, p. 21-24, acrescentamos as siglas em português do livro ou de fragmento póstumo: NT ( $O$ nascimento da tragédia); VM (Sobre verdade e mentira no sentido extra-moral); HH (Humano, demasiado humano (Vol. 1)); A (Aurora); GC (A gaia ciência); BM (Para além de bem e mal); GM (Para a genealogia da moral); CI (Crepúsculo dos ídolos); FP (fragmento póstumo). Nas citações, o algarismo arábico indica o aforismo ou a seção. Em $G M$, o algarismo romano anterior ao arábico indica a dissertação do livro. Em CI, o algarismo arábico, indicando a seção, segue-se ao título do capítulo. Para os fragmentos póstumos, os algarismos arábicos, que se seguem ao ano, indicarão o fragmento póstumo. Às siglas KSA ou KGW se seguirão um ponto e a página correspondente à edição. As citações dos textos de Nietzsche não são acompanhadas do nome do autor. São de nossa responsabilidade as traduções dos textos em língua estrangeira cuja autoria não é de Nietzsche.

${ }^{2}$ Doutorando em Filosofia pela Universidade de São Paulo (USP) e pela Universidade de Paris 1 PanthéonSorbone; bolsista da Fapesp e mestre em filosofia pela USP.
} 
A ciência se faz presente no pensamento de Nietzsche em diversas formas. A começar por seu próprio métier enquanto professor de filologia clássica de 1869 a 1879 na Universidade da Basileia. Em seguida, por sua prática de leitura, que não se restringe ao domínio específico da disciplina a que se dedica profissionalmente, mas, antes, dá mostras de um interesse crescente por ciências cada vez mais diversas, como química, física, biologia, medicina, etnologia e astronomia, para mencionar só algumas de uma longa lista ${ }^{3}$. Não é de surpreender então, levando-se em conta os dois pontos precedentes, que as questões científicas de seu tempo não só lhe despertem a atenção como sejam tomadas como seus próprios problemas ${ }^{4}$. Mais até, Nietzsche parece pretender conferir uma fundamentação científica pelo menos aos seus conceitos centrais, como vontade de potência e eterno retorno, e aos seus eixos investigativos fundamentais, como é o caso do domínio moral ${ }^{5}$. Por fim, é preciso sublinhar que, dos primeiros aos últimos escritos, Nietzsche faz da ciência e sua ligação com a filosofia um problema e objeto de reflexão, que submete ao exame teórico e à apreciação axiológica.

Mas a presença da ciência na filosofia de Nietzsche não se deixa explicar pela simples contingência de um interesse pessoal. É bem outro o caso: em sua época, são o próprio pensamento científico e a exigência de cientificidade que se impõem de maneira incontornável. A prosperidade, ao menos presumida, do conhecimento científico reflete-se diretamente em seu reconhecimento cultural, tanto no que diz respeito à sua extensão quanto ao seu estatuto ${ }^{6}$. Assistindo ao aumento substancial de seu universo temático, as ciências

\footnotetext{
${ }^{3}$ Sobre as ciências pelas quais se interessou Nietzsche, cf., entre outros, os três volumes da biografia de Janz (1984, v. 1 e v. 2; 1985, v. 3), Nietzsche and Science (MOORE, G.; BROBJER, T. (Org.), 2004), Nietzsches Wissenschaftsphilosophie: Hintergründe, Wirkungen und Aktualität (HELMUT, H.; ABEL, G.; BRUSOTTI, M. (Org.), 2012), Handbuch. Nietzsche und die Wissenschaften (HELMUT, H.; HELLER, L. (Org.), 2014), afora inúmeros artigos (publicados, por exemplo, nos Nietzsche-Studien). Sobre quais obras o filósofo possuía, cf. Nietzsches persönliche Bibliothek (CAMPIONI, G.; D'IORIO, P.; FORNARI, M. C.; FRONTEROTTA, F.; ORSUCCI, A., 2003); sobre os empréstimos da biblioteca na universidade em que era professor, cf. Crescenzi (1994, p. 388-442). Vale notar que, afora a filologia, Nietzsche não chegou a praticar outra ciência. Além disso, são várias as formas pelas quais trava contato com as ciências: desde a leitura de autores como Lange e Schopenhauer, passando por escritos de vulgarização até trabalhos mais especializados.

4 "Com a teoria das forças", sustenta Scarlett Marton (2000, p. 66), "o filósofo pretende resolver o que constitui um dos problemas centrais para a ciência da época”: a distinção entre orgânico e inorgânico.

${ }^{5}$ Kaufmann (1974, p. 86) afirma: "Nietzsche, não menos do que Hegel, quis que a filosofia se tornasse científica, wissenschaftlich - mas ciência não significa a mesma coisa para os dois pensadores": enquanto para este, ciência equivale a sistema, para aquele, ciência é, além de rigor, experimentalismo e boa vontade para, se necessário, abandonar antigas posições.

${ }^{6}$ Reconhecendo a "admiravelmente elevada pirâmide do conhecimento do presente", (GT/NT 15, KSA 1.100), o próprio Nietzsche parece em alguns momentos celebrar a continuidade da ciência, após a filologia ter encontrado o método correto da boa leitura (MA I, HH I 270, KSA 2.223), ou ainda simplesmente constatar a felicidade motivada pelo fato de que a ciência produz coisas que se sustentam, até em meio à crença na mutabilidade de tudo o que é humano (FW/GC 46, KSA 3.411-412). Por outro lado, mesmo ao constatar que "a ciência floresce hoje e expressa em sua face a boa consciência" (JGB/BM 204, KSA 5.131), Nietzsche não deixa de caracterizar
} 
começam a ocupar-se de assuntos até então considerados exclusivos de outras áreas, como a teologia e a filosofia. Além de ampliar o seu domínio, o estatuto do conhecimento científico passa a gozar de notável credibilidade, a tal ponto que agora muitos depositam nele, no conhecimento científico, e não mais na teologia ou na filosofia, as esperanças de um saber verdadeiro ou pelo menos as credenciais de um saber mais rigoroso. Nesse contexto, um filósofo se vê compelido ao diálogo com a ciência ${ }^{7}$.

Tal diálogo, no caso da obra de Nietzsche, assume por vezes a aparência de uma contribuição mútua amistosa; em outros momentos, porém, reveste-se de um aspecto manifestamente conflituoso, em que estão em jogo uma espécie de delimitação territorial e o estabelecimento da hierarquia que deve reger a relação entre ciência e filosofia.

Comecemos por examinar a face, por assim dizer, mais colaborativa e amigável do diálogo entre ambas. Já no escrito Fatum und Geschichte, de 1862, Nietzsche defende que uma especulação bem fundamentada só se pode construir com base na história e nas ciências naturais $^{8}$. É bem cedo, portanto, que concebe a necessidade de conciliar filosofia e ciência, esta a refrear as especulações etéreas daquela ${ }^{9}$. Posteriormente, tal conciliação receberá formulações em tom programático, tal como lemos, por exemplo, no primeiro parágrafo de Humano, demasiado humano e na nota acrescentada ao término da primeira dissertação de Para a genealogia da moral.

No primeiro parágrafo de Humano, demasiado humano, Nietzsche contrapõe sua filosofia histórica à filosofia metafísica. Esta pressupõe oposições, nega a origem de um dos opostos a partir do outro e, por fim, atribui uma origem milagrosa e mais elevada a tudo o que se estima mais valioso. A filosofia histórica, por sua vez, nega as oposições mesmas: o que se toma como um dos opostos é apenas a sublimação do elemento básico, volatilizado e agora visível somente a uma observação mais perspicaz; segundo esse modo de observar, a rigor não haveria, por exemplo, ações não egoístas. Ocorre que uma tal filosofia histórica não se pode concebê-la separada da ciência natural; mais até, é "somente em virtude da elevação das

“[...] a crença na ciência, que agora está aí incontestavelmente [...]” (FW/GC 344, KSA 3.576, trad. RRTF) como meramente "a boa fé na ciência, o preconceito favorável a ela" (FW/GC 123, KSA 479).

${ }^{7}$ No primeiro parágrafo de Humano, demasiado humano, intitulado justamente Química dos conceitos e sentimentos, Nietzsche fala de uma "filosofia histórica, que não se pode mais, de maneira alguma, conceber como separada da ciência natural" (MA I/ HH I 1, KSA 2.23).

${ }^{8} \mathrm{Cf}$. Fatum und Geschichte (KGW I/2.430 e seq.).

${ }^{9}$ Ideia que, no essencial, permanecerá até 1888. Cf. CI, A “razão” na filosofia, 3, KSA 6.75-76. 
ciências particulares atuais" que é possível aquela "química das representações e dos sentimentos morais, religiosos, estéticos" (MA I, HH 1, KSA 2.24) ${ }^{10}$.

Semelhante ideia de dependência da filosofia em relação às ciências será retomada como princípio norteador na nota acrescentada ao término da primeira dissertação de Para a genealogia da moral. Ali, Nietzsche começa por conclamar filólogos, historiadores e cientistas da linguagem, ao lado dos eruditos em filosofia, a investigarem "a história da evolução dos conceitos morais". Em seguida, convoca outros domínios científicos a tomarem parte nesta empresa: as tábuas de bens conhecidas pela história e pelas pesquisas etnológicas, além de um exame psicológico, carecem igualmente de uma análise por parte da medicina e da fisiologia, as quais deveriam estabelecer um intercâmbio frutífero com a filosofia. Ao concluir sua nota, porém, Nietzsche não se satisfaz com o apelo às mencionadas ciências, por diversas que sejam, e generaliza, sublinhando: "Todas as ciências devem doravante preparar a tarefa futura do filósofo: por tal tarefa entende-se que o filósofo deve resolver o problema do valor, que ele deve determinar a hierarquia dos valores" (GM/GM I, 17, nota, KSA 5.289).

Assim, para evitar perder-se na especulação metafísica, a filosofia histórica ou a genealogia dos valores não devem prescindir do trabalho das ciências, mas necessariamente fundamentar-se nele. Neste sentido, filosofia histórica ou genealogia dos valores só são possíveis graças às ciências. Por outro lado, vê-se bem a hierarquia que tem de presidir a tal relação: a empresa científica deve subordinar-se à filosofia, cuja tarefa é resolver o problema dos valores.

É, com efeito, em termos de "dominação" que Nietzsche entende a relação entre filosofia e ciência, como se lê num fragmento póstumo do início da década de 1870 cujas ideias permanecerão, no essencial, até os últimos escritos, (Nachlass/FP 1872-1873, 19[24], KSA 7.424). Mostrando-se já nesse momento contrário à emancipação da ciência, que outrora se livrou da teologia e agora pretende livrar-se também da filosofia (Nachlass/FP 1872-1873, 19[28], KSA 7.425), Nietzsche continuará a avaliar como nociva a inversão hierárquica entre filosofia e ciência que corre o risco de ter lugar diante de seus olhos (JGB/BM 204, KSA 5.129). Por mais que em sua época a ciência floresça e a filosofia seja digna de desconfiança, daí não se deve seguir, ajuíza o autor de Para além de bem e mal, "a descrença na tarefa senhorial e na dominação da filosofia” (JGB/BM 204, KSA 5.131). Se os homens de ciência

\footnotetext{
${ }^{10}$ É a ciência, afirma Nietzsche pouco adiante, que poderá traçar a "história genética do pensar", mostrando como nossa concepção de mundo se baseia em erros originados durante a evolução orgânica. Mesmo assim, adverte o autor em seguida, só de uma pequena parte de tais erros pode nos liberar a ciência (MA I/HH I 16, KSA 2.36, trad. RRTF).
} 
são condição necessária para a realização de tal tarefa - tarefa que neste contexto consiste em criar valores -, eles, esses homens de ciência, não passam de instrumentos dos autênticos filósofos (JGB/BM 211, KSA 5.144-145).

É que tais filósofos, segundo Nietzsche, são dotados de um olhar superior, capaz de captar o problema do valor de maneira mais global e de considerá-lo a partir de múltiplos pontos de vista ${ }^{11}$. Mas também no que diz respeito ao desenvolvimento de tal olhar filosófico a ciência desempenha um papel central. É verdade, as ciências atingiram tamanha amplitude que podem representar até mesmo um perigo para o desenvolvimento do filósofo, na medida em que este corre o risco de deter-se e especializar-se num ponto determinado e não atingir aquele olhar mais amplo e superior (JGB/BM 205, KSA 5.132). Mas, se insiste que os autênticos filósofos não se confundem com trabalhadores filosóficos nem com homens científicos, Nietzsche afirma por outro lado que "pode ser necessário para a educação do filósofo efetivo que ele próprio tenha também estado em todos esses graus, nos quais seus servidores, os trabalhadores científicos da filosofia, se detêm - têm de se deter" (JGB/BM 211, KSA 5.144).

Levando-se em conta o que expusemos até o momento, temos, em linhas gerais, o seguinte cenário: reservando à filosofia uma tarefa própria e hierarquicamente superior - a saber, resolver o problema dos valores, isto é, estabelecer a história dos valores, criar valores e determinar sua hierarquia -, Nietzsche resguarda a soberania da filosofia sobre a ciência; a filosofia, porém, não deixa de depender da ciência, já que esta cumpre um papel decisivo na educação do verdadeiro filósofo e se revela uma condição necessária para a consecução daquela tarefa propriamente filosófica.

Neste ponto, parece-nos indispensável, entretanto, indicar uma última dificuldade: como a ciência, que repousa em certos valores predominantes, pode contribuir para a tarefa filosófica de resolver o problema dos valores?

De fato, ao mesmo tempo em que não se pode mais filosofar sem ciência, a ciência repousa, ela própria, em pressupostos filosóficos ${ }^{12} \mathrm{e}$, a rigor, se constrói a partir de um

\footnotetext{
${ }^{11}$ Dotados daquilo que Nietzsche designa como "Überblick, Umblick, Niederblick" (JGB/BM 205, KSA 5.132), os autênticos filósofos são aptos a "percorrer o circuito de valores e de sentimentos de valor humanos e, com múltiplos olhos e consciências, poder olhar, da altura para toda distância, da profundeza para toda altura, do canto para toda amplidão" (JGB/BM 211, KSA 5.144, trad. RRTF).

${ }^{12}$ Cf. Nachlass/FP 1872-1873, 19[24], KSA 7.424.
} 
dogmatismo religioso e filosófico: a crença no valor absoluto da verdade ${ }^{13}$. É por isso que após exortar, ao final da primeira dissertação de Para a genealogia da moral, as ciências a contribuírem com a tarefa filosófica de estabelecer a história dos conceitos morais e de determinar a hierarquia dos valores, Nietzsche empreende, nas páginas subsequentes, uma crítica mordaz à ciência. Crítica em cujo ponto culminante o autor chega mesmo a asseverar: “[...] quem, por exemplo, se propõe a pôr a filosofia 'sobre rigoroso fundamento científico', precisa antes pôr, não somente a filosofia, mas também a própria verdade de cabeça para baixo [...]" (GM/GM III, 24, KSA 5.400, trad. RRTF).

Obedecendo, em linhas gerais, a uma dupla orientação, a crítica ao pensamento científico é tanto epistemológica quanto axiológica - ainda que a crítica epistemológica encerre uma dimensão axiológica. Ao examinar em termos epistemológicos certas noções científicas fundamentais, como o conceito de causa e a teoria da legalidade da natureza, Nietzsche procura defender que, ao contrário do que pretendem alguns, as ciências - assim como, aliás, os sistemas filosóficos - não alcançam verdades absolutas nem explicam o mundo (JGB/BM 14, KSA 5.28), mas se limitam a apresentar antropomorfismos (WL/VM 1, KSA 1.880), descrições (FW/GC 112, KSA 3.472-473), ficções reguladoras, hipóteses, pontos de vista experimentais e provisórios (FW/GC 344, KSA 3.574-575) e interpretações (JGB/BM 14 e 22, KSA 5.28 e 37) condicionadas por certas necessidades de sobrevivência ou de aumento de potência.

Ao perscrutá-la de um ponto de vista axiológico, o filósofo julga que a ciência de sua época tem por pressuposto um dogmatismo a um só tempo filosófico, representado exemplarmente por Platão, e religioso, nomeadamente cristão: a ciência se edifica sobre a crença metafísica no valor absoluto da verdade (GM/GM III, 24, KSA 5.398-401). Além de semelhante fé, a ciência deixa-se guiar por toda sorte de preconceitos, que Nietzsche procura, durante a sua obra inteira, trazer à luz e criticar: desde o altruísmo cristão até os "instintos democráticos da alma moderna", que estão na base da teoria física da "legalidade da natureza" (JGB/BM 22, KSA 5.37, trad. RRTF).

Mas como poderiam as ciências, nessas condições, contribuir para investigar o problema do valor dos valores, tal como conclama o final da primeira dissertação de Para a genealogia da moral, se elas próprias repousam em tais valores, muitas vezes, se não sempre, inconscientemente?

${ }^{13}$ Cf. FW/GC 344, KSA 3.574-577. A dimensão ascética da ciência será reexaminada com vagar em Para a genealogia da moral, em que o autor procura mostrar que a ciência não é adversária, mas rebento do ideal ascético (em particular GM/GM III, 23, 24, 25, 28, KSA 5.395-405 e 411-412). 
E, no limite, não se trata de eliminar todo e qualquer pressuposto da ciência, pois, como Nietzsche sentencia imediatamente antes de criticar a pretensão de estabelecer uma filosofia sobre fundamentos científicos rigorosos: "Não há, a julgar rigorosamente, nenhuma ciência 'sem pressuposto', o pensamento de uma tal ciência é impensável, é paralógico: uma filosofia, uma 'crença', tem sempre antes de estar aí, para que a partir dela a ciência ganhe uma direção, um sentido, um limite, um método, um direito a estar aí, à existência" (GM/GM III, 24, KSA 5.400, trad. RRTF).

Para concluir, gostaria de dizer que, guardando-se de extremismos, a posição de Nietzsche parece caracterizar-se antes de tudo por suas nuances. Se o autor se dá conta de que em sua época não é mais possível filosofar ignorando a ciência, do florescimento científico não se seguem necessariamente o descrédito e o fim da filosofia, tampouco a supremacia da ciência. Ainda que os dois pretensos domínios de saber travem um combate, para muitos, de vida ou morte, o melhor a fazer não é defender um e atacar o outro incondicionalmente, mas estabelecer uma relação de controle mútuo: de um lado, a ciência deve conter a dimensão especulativa da filosofia, enquanto, de outro, cabe à filosofia refrear o dogmatismo científico, que se traduz num impulso ilimitado de conhecimento e na crença no valor absoluto da verdade. Por certo, o próprio Nietzsche não concebe tal controle mútuo sob um prisma pacífico, mas em termos de combate, dominação e hierarquia: ele se opõe à pretensão de emancipação da ciência e lhe prescreve subordinação à filosofia, (supostamente) a única autorizada a resolver o problema dos valores, inclusive do valor da ciência. Com isso, o filósofo parece impor uma limitação de direito ao domínio científico e garantir a autoridade filosófica sobre as ciências. Mesmo assim, a ciência cumpre um papel decisivo na educação do autêntico filósofo e se revela mesmo condição necessária para a consecução daquela tarefa especificamente filosófica. Neste ponto, porém, apresenta-se ainda uma última dificuldade, que procuramos apenas esboçar: se a ciência deve contribuir para a tarefa filosófica de resolver o problema dos valores, nem por isso Nietzsche deixa de apontar que a própria ciência se encontra sob a orientação de determinados valores predominantes em sua época, mas criticáveis segundo a apreciação do filósofo.

\section{Referências}


CAMPIONI, Giuliano; D’IORIO, Paolo; FORNARI, Maria Cristina; FRONTEROTTA, Francesco; ORSUCCI, Andrea. Nietzsches persönliche Bibliothek. Berlim: Walter de Gruyter, 2003.

CRESCENZI, Luca. "Verzeichnis der von Nietzsche aus der Universitätsbibliothek in Basel entliehenen Bücher (1869-1879)”. In: Nietzsche-Studien 23, 1994, p. 388-442.

HELMUT, Heit; ABEL, Günter; BRUSOTTI, Marco (Org.). Nietzsches Wissenschaftsphilosophie: Hintergründe, Wirkungen und Aktualität. Berlim/Boston: Walter de Gruyter, 2012.

HELMUT, Heit; HELLER, Lisa (Org.). Handbuch. Nietzsche und die Wissenschaften. Berlim/Boston: Walter de Gruyter, 2014.

JANZ, C. P. Nietzsche: Biographie. Tome I: Enfance. Jeunesse. Les années bâloises. Tradução de Marc B. de Launay. Paris: Éditions Gallimard, 1984.

Nietzsche: Biographie. Tome II: Les dernières années bâloises. Le libre philosophe. Tradução de Pierre Rusch. Paris: Éditions Gallimard, 1984.

Nietzsche: Biographie. Tome III: Les dernières années du libre philosophe. La maladie. Tradução de Pierre Rusch e Michel Vallois. Paris: Éditions Gallimard, 1985.

KAUFMANN, Walter. Nietzsche. Philosopher, Psychologist, Antichrist. Princeton: Princeton University Press, $4^{\mathrm{a}}$ ed., 1974.

MARTON, S. Nietzsche: das forças cósmicas aos valores humanos. $2^{\mathrm{a}}$ edição. Belo Horizonte: Editora UFMG, 2000.

MOORE, Gregory; BROBJER, Thomas (Org.). Nietzsche and Science. Aldershot: Ashgate, 2004.

NIETZSCHE, Friedrich. Werke. Kritische Gesamtausgabe in 33 Bänden [KGW]. Giorgio Colli e Mazzino Montinari (Org.). Berlim e Nova York: Walter de Gruyter, 1963 e seq.

Sämtliche Werke. Kritische Studienausgabe [KSA]. Giorgio Colli e Mazzino Montinari (Org.). München: Walter de Gruyter, 1999.

Friedrich Nietzsche. Obras incompletas. Tradução de Rubens Rodrigues Torres Filho. São Paulo: Editora Nova Cultural, 2000. 
